\title{
POR UMA HISTÓRIA CRÍTICA DA COLÔMBIA (1853-1953)
}

\author{
POR UNA HISTORIA CRÍTICA DE COLOMBIA (1853-1953)
}

FOR A CRITICAL HISTORY OF COLOMBIA (1853-1953)

\author{
Giovana Eloá Mantovani MULZA ${ }^{1}$
}

RESUMO: O presente trabalho consiste em uma revisão bibliográfica acerca das principais discussões concernentes à História da Colômbia entre 1853 e 1953, ínterim singular para sua atual configuração sociopolítica e econômica. Problematizamos, por conseguinte, textos constitucionais e debatemos fontes secundárias com o intuito de compreender o Liberalismo Radical (1863-1885), a Regeneración (1885-1904) e a reconstituição democrática (1904-1953). Rechaçando uma simples e irrisória enumeração dos presidentes colombianos dessas conjunturas históricas, nosso trabalho transcende os manuais colombianos caracterizados pelo cunho político-factual, os quais são objeto das críticas do revisionismo histórico colombiano. Uma contínua dificuldade repousara na escassez de obras historiográficas referentes à História da Colômbia disponíveis em âmbito brasileiro. Ademais, o estudo do passado colombiano constitui em uma tarefa fundamental da historiografia latino-americana, tornando-se inclusive uma necessidade intelectual. Afinal, compreender a trajetória da Colômbia enquanto país integrante da América Latina torna-se imprescindível para o estudo dos demais países que compõem a região.

PALAVRAS-CHAVE: História da Colômbia. América Latina. Revisão bibliográfica.

RESUMEN: El presente trabajo consiste en una revisión bibliográfica sobre las principales discusiones sobre la Historia de Colombia entre 1853 y 1953, un interino singular por su configuración sociopolítica y económica actual. Por lo tanto, problematizamos textos constitucionales y debatimos fuentes secundarias para comprender el liberalismo radical (1863-1885), la regeneración (1885-1904) y la reconstitución democrática (1904-1953). Rechazando una enumeración simple y burlona de los presidentes colombianos de estas coyunturas históricas, nuestro trabajo trasciende los libros de texto colombianos caracterizados por la naturaleza político-fáctica, que son objeto de crítica del revisionismo histórico colombiano. Una dificultad continua ha sido la escasez de trabajos historiográficos sobre la historia de Colombia disponibles en Brasil. Además, el estudio del pasado colombiano es una tarea fundamental de la historiografía latinoamericana, llegando incluso a ser una necesidad intelectual. Después de todo, comprender la trayectoria de Colombia como país miembro de América Latina es esencial para el estudio de los otros países que conforman la región.

PALABRAS CLAVE: Historia colombiana. América Latina. Revisión bibliográfica.

1 Universidade Estadual de Maringá (UEM), Maringá - PR - Brasil. Mestranda em História. ORCID: https://orcid.org/0000-0001-5911-9370.E-mail: gio_mantovani@hotmail.com 
ABSTRACT: The present work constitutes in a bibliographical revision about the main discussions concerning the History of Colombia between 1853 and 1953, unique period for its current sociopolitical and economic configuration. We therefore problematize constitutional texts and discuss secondary sources with the aim of understanding Radical Liberalism (18631885), Regeneración (1885-1904) and democratic reconstitution (1904-1953). Rejecting a simple and derisory enumeration of the Colombian presidents of these historical conjunctures, our work transcends the Colombian manuals characterized by the political-factual, which are the object of criticism of the Colombian historical revisionism. A continuing difficulty rested on the scarcity of historiographical works related to the History of Colombia available in Brazil. In addition, the study of the Colombian past constitutes a fundamental task of the Latin American historiography, becoming even an intellectual necessity. After all, understanding the trajectory of Colombia as an integral part of Latin America becomes essential for the study of the other countries that make up the region.

KEYWORDS: History of Colombia. Latin America. Literature review.

\section{Introdução}

O Estado colonial espanhol, em especial sob o domínio da dinastia dos Burbons, se concentrou em extrair as riquezas da então Nova Granada, em construir uma rede ineficiente de instituições - tais como monopólios e restrições comerciais - e em expropriar as terras dos povos indígenas. Apesar de algum dinamismo econômico, isto conduziu a uma economia doméstica estancada. A independência teve pouco impacto sobre esta situação até a revolução liberal de 1850, quando muitas das estruturas coloniais foram revogadas. Sem dúvida, ainda quando os liberais aboliram a escravidão e os monopólios, e permitiram que os povos indígenas tivessem terras em condição de pleno domínio, suas políticas levaram a uma contração de mais de quarenta anos na atividade econômica. Para William Paul Mcgreevey (2015), a situação foi de alguma forma semelhante ao colapso da União Soviética. Se bem todo o mundo estava de acordo em que as instituições econômicas soviéticas eram massivamente ineficientes, seu colapso provocou uma queda econômica no Leste europeu e nas antigas repúblicas soviéticas. Tanto na Colômbia de 1850 quanto nas repúblicas soviéticas de 1989, os pré-requisitos básicos para o desenvolvimento econômico não estavam fixos naqueles lugares. Os liberais colombianos tornariam esse desenvolvimento ainda mais difícil de ser alcançado.

As reformas fiscais posteriores a 1850 acabaram por quebrar o Estado central e o hiper federalismo da Constituição de Rionegro de 1863 deixou esse Estado central sem o monopólio do controle da violência. Dessa forma, não existia uma entidade capaz de promover bens públicos, como infraestrutura ou educação escolar, ou promover o desenvolvimento econômico. A consequente ausência de intervenção estatal, a desordem e as guerras civis contribuíram 
consideravelmente para o declínio econômico. O declínio se transformou em expansão por volta de 1890, quando a economia cafeeira despertou, se constituiu a infraestrutura básica dos transportes - em especial as ferrovias - e houve uma transição a um crescimento sustentável.

Discorrer sobre a história da Colômbia de um século a outro - conforme expressão de Muñoz (2016) - não consiste em uma tarefa isenta de intenções. Certas dificuldades foram encontradas ao longo da formulação desse trabalho. Um desafio primevo foi compreender a história colombiana enquanto uma realidade intrínseca ao contexto latino americano dos séculos XIX e XX. Para sanar possíveis dúvidas, torna-se conivente analisar a própria construção do significado do termo América Latina. Como apresentam R. L. Farret e S. R. Pinto (2011, p. 31), a mudança do termo Hispano-américa para América Latina seria mediada pelos descendentes das antigas elites criollas, os quais visavam promover a formulação de uma identidade singular para o subcontinente. Apesar de consolidar-se no decorrer do século XIX, o nome "América Latina" fora construído com o intuito de distinguir os hispano-americanos dos estadunidenses e europeus (FARRET; PINTO, 2011). Os países que passaram a compor a América Latina diziam ser nações livres e unidas em torno de interesses e vínculos culturais. Contestavam, sobretudo, a influência estadunidense no restante do continente americano ${ }^{2}$. A América Latina se opunha à sua antítese: a América Saxônica.

Os Estados Unidos despontavam no século XIX como uma potência regional. A partir da criação da Doutrina Monroe em 1823, com seu lema "A América para os americanos", suas ambições imperialistas em relação aos países do continente ficaram claras. Tratando-se apenas, inicialmente, de uma advertência às potências europeias, no sentido de que não tentassem reativar o domínio colonial sobre o continente, essa doutrina passou a ser empregada, ainda no século XIX, como justificativa intervencionista para todo o continente americano. Seu lema poderia ser interpretado, portanto, como "A América para os norte-americanos". A força de seu imperialismo regional pôde ser sentida pelo México no final dos anos 1840, quando da guerra travada pelos dois países e que teve como saldo a cessão aos Estados Unidos de aproximadamente 2,4 milhões de quilômetros quadrados do território mexicano. Além disso, vale lembrar a façanha de William Walker (18241860), norte-americano que, a partir de 1855 , passou a ser o grande chefe político da Nicarágua (FARRET; PINTO, 2011, p. 34).

A necessidade de afirmar a excepcionalidade dos Estados Unidos é a chave da cultura política norte-americana. [...] Essa mesma necessidade obsessiva de afirmar a excepcionalidade dos Estados Unidos aparece nas discussões sobre a política externa norte-americana. A mensagem subjacente é clara: os Estados Unidos merecem confiança, seja no Iraque ou em qualquer outra parte, porque

${ }^{2}$ A gradual substituição da influência inglesa nos antigos domínios espanhóis para a intervenção estadunidense fora alvo das críticas de José Martí. Para mais informações acerca do assunto, recomendamos a leitura Luiz Alberto Moniz Bandeira (2009). 
os Estados Unidos são justos e altruístas, e assim o tem demonstrado ao longo de dois séculos de história (BANDEIRA, 2009, p. 25)

A Colômbia comunga de muitos elementos comuns aos países do continente americano, tal como a língua espanhola e a tradição católica - características dos Estados descendentes do domínio hispânico. Processos e fenômenos históricos sincrônicos, como a emancipação política e o conflito liberalismo-protecionismo no final do século XIX, permitem ao pesquisador identificar a similitude da história da Colômbia ao conjunto das nações da América Latina ${ }^{3}$. Para Ailton de Souza (2011), o conceito de "América Latina" nasceu ainda no século XV, durante a conquista e a colonização do continente americano pelos ibéricos. Muitos dos usos do termo possuíam um cunho preconceituoso e equivocado. Assim, “[...] grande parte da literatura histórica estrangeira contemplava a região a partir de visão negativa e até mesmo discriminatória em relação ao seu povo, sua cultura ou aspectos geográficos." (SOUZA, 2011, p. 31). A terminologia "América Latina" possui uma origem essencialmente francesa, derivado de Amérique Latine, sendo utilizado com o intuito de legitimar o domínio da França sobre o atual México. Desde então, o significado desse conceito modificou sua conotação, embora continue a ser usado para categorizar os países de colonização ibérica.

Todavia, apesar das semelhanças linguísticas e religiosas, o protagonismo das elites político-econômicas constituiu uma característica, em partes, singular da Colômbia ao longo do período ao qual nos propomos a analisar. Afinal, “[...] desde o momento das independências até a primeira metade do século XX, os projetos de construção nacional foram dirigidos pelas elites militares, agrícolas, comerciais, industriais e bancárias [...]” (MUÑOZ, 2016, p. 13, tradução nossa $\left.{ }^{4}\right)$.

À medida que construirmos nossa narrativa acerca da Colômbia de um século a outroempregando a expressão de Rafael Rubiano Muñoz (2016) -, se tornará explícito ao leitor nossas reivindicações por uma História crítica da Colômbia. Cronologicamente, partiremos do governo de José Hilário López (1849-1853), finalizando nossas discussões com o período protofascista de Laureano Gómez (1949-1953). Apesar de empregarmos balizas cronológicas políticas, nosso estudo não se consistirá em uma enumeração cansativa dos presidentes colombianos. A Colômbia, enquanto nação inserida nos padrões latino-americanos, demanda

${ }^{3}$ De fato, em editoração exemplar, Leslie Bethell (2004) organizara a História latino-americana sob categorias temporais, comungando implicitamente do ideal de que certas constantes temáticas podem ser encontradas no estudo do subcontinente.

${ }^{4}$ [...] desde el momento de las independencias hasta la primera mitad del siglo XX, los proyectos de construcción nacional fueron dirigidos por las elites militares, hacendarias, eclesiales, comerciantes, industriales y bancarias [...] (MUÑOZ, 2016, p. 13). 
de uma história de caráter crítico, cujos novos temas, objetos e abordagens necessitam superar a narrativa factual e eminentemente política-estatal.

“A construção da paz é mais difícil que a conquista da paz. Uma coisa é silenciar fuzis e outra coisa é construir a paz. Leva mais tempo, mais esforço para modificar sentimentos, preconceitos, modificar modos de pensar" (MANETTO; TORRADO, 2018). Em entrevista concedida ao El País Brasil, o ex-presidente colombiano Juan Manuel Santos (2010-2018) evidencia a preocupação que conduzira seu mandato governamental: a construção da paz. $\mathrm{O}$ argumento vai ao encontro das proposições de Gonzalo Sánchez Gómez (1990), para quem guerra e política integram historicamente a nação colombiana.

Guerra e política, ordem e violência, violência e democracia, e no limite, vida e morte, são algumas das múltiplas oposições e complementaridades a partir das quais se faz decifrável a história colombiana. Para dizer a verdade, se tem algo que se destaca no devir histórico e na cotidianidade deste país é a não resolução dos antagonismos, sua teimosa coexistência, como se formassem parte de uma disposição natural das coisas (GÓMEZ, 1990, p. 07, tradução nossa ${ }^{5}$.

A violência - embora não consista em uma constante na História colombiana tal qual se apresenta no Paraguai (QUINTEROS; MOREIRA, 2016) - constitui um tema que deve ser abordado pela história antropológica e pela sociologia histórica, não somente com o intuito de compreender a recente ação das FARC, mas sobretudo para o estudo da violência política e étnica no país. Essa lacuna, cuja resolução transcende nossos propósitos, merece ser abordada pela atual historiografia colombiana. Manifestada na governança de Laureano Gonzáles, a violência será abordada por nós ao longo das formulações finais do texto, permanecendo como uma constante em nossa narrativa.

O que é notável, de um século a outro na Colômbia, é como não se tem podido consolidar a democracia como regime ou como mentalidade. É muito notório também que no terreno da integração nacional e no campo ideológico político, a oposição, a divergência e as diferenças, se resolviam mediante o extermínio, o cárcere, o exílio ou a violência. Outro dos elementos de análise que surgem ante a interpretação de um século de processos políticos no país, é que a guerra tem sido um elemento ou um fator consubstancial da identidade e de sua nacionalidade, e de outro lado, que a legalidade e a ilegalidade, a institucionalidade e a violência, a democracia e a anarquia têm convivido no que nos últimos anos se tem concebido desde a sociologia política como o "Almedrón" ou seja, uma coexistência da ordem e da violência, ou do

${ }^{5}$ Guerra y politica, orden y violencia, violencia y democracia, y en el limite, vida y muerte, son algunas de las múltiples oposiciones y complementariedades a partir de las cuales se hace decifrable la historia colombiana. A dicer verdade, si hay algo que obsesiona en el devenir histórico y en la cotidianidad de este país es la no resolución de los contrários, su terca coexistencia, como si formaran parte de una certa disposición natural de las cosas. (GÓMEZ, 1990, p. 07). 
funcional racional como formas de irracionalidade (MUÑOZ, 2016, p. 16-17; tradução nossa ${ }^{6}$ ).

Estudar o passado colombiano a partir do Brasil não constitui em uma tarefa fácil. Buscaremos atender sucintamente a uma demanda e instigar a produção de novas investigações.

\section{O Liberalismo radical}

Com o fim da Gran Colombia em 1849, ascenderiam os Partidos Liberal e Conservador, cujas disputas passariam a conduzir o jogo político colombiano. Assim, "Explosivas e frequentes guerras civis, envolvendo porção considerável da população, alternaram-se com breves períodos de paz durante todo o século XIX. Tal rivalidade cristalizou um sistema bipartidário, que [...] resiste há mais de cento e cinquenta anos." (CHECCHIA, 2000, p. 02). Durante as décadas de 1850 e 1880, portanto, prevaleceria no país o Partido Liberal. De fato, sob qual explicação deveríamos nos apoiar para compreender as reformas liberais situadas entre 1853 e 1885-86? Em trabalho notório para o campo da História das Religiões, Religiosidades e Crenças, Danièle Hervieu-Léger (2008), cujo primeiro capítulo em O peregrino e o convertido se intitula "A religião espedaçada: Reflexões prévias sobre a modernidade religiosa", permitenos compreender essas reformas liberais enquanto um momento de modernização da Colômbia. Afinal, segundo a autora, a modernidade corresponde ao momento em que se desenvolve a secularização do Estado e a laicização da política, elementos verificados na Colômbia ultraliberal no final do século XIX.

Na Constitución de Rionegro, publicada originalmente em 1863, os estados que então compunham a Colômbia - nomeadamente Antioquia, Bolívar, Cauca, Cundinamarca, Magdalena, Panamá, Santander, e Tolima -, passam a auferir uma ampla soberania, evidenciando a descentralização estabelecida no regime político do país. Nessa mesma carta constitucional, estabelecia-se a necessidade de que esses estados deveriam ter como base um “Governo popular, eletivo, representativo, alternativo e responsável.” (COLOMBIA, 1863, tradução nossa ${ }^{7}$ ). O mundo pós-1848 caminhava a passos largos para um novo padrão político

${ }^{6}$ Lo que es notable, de un siglo a outro en Colombia, es cómo no se ha podido consolidar la democracia como régimen o como mentalidad. Es muy notorio también que en el terreno de la integración nacional y las diferencias, se resolvían mediante el exterminio, la cárcel, el exilio o la violencia. Otro de los elementos de análisis que surgen ante la interpretación de un siglo de preocesos políticos del país, es que la guerra há sido um elemento o un factor consubstancial de la constitución de la identidad y de su nacionalidad, y de otro lado, que la legalidad y la ilegalidad, la institucionalidad y las violencias, la democracia y la anarquia han convivido en lo que en los últimos años se ha concebido desde la sociología política como el "Almendrón" o sea, una coexistencia del orden y la violencia, o de lo funcional racional con formas de irracionalidad. (MUNOZ, 2016, p. 16-17).

${ }^{7}$ Gobierno popular, electivo, representativo, alternativo y responsable. 
democrático e liberal, e a Colômbia não estava isenta dessa realidade ${ }^{8}$. As reformas que inauguraram essa ordem liberal acabaram por consolidar os partidos políticos e promover o crescimento das sociedades democráticas. Assim, a participação corporativa e hierárquica dos cidadãos colombianos na política do país no começo do século XIX dará lugar a uma participação mais efetiva na Colômbia liberal. Além disso, se estabeleceria a efetiva extinção do regime escravista na Colômbia. A liberdade torna-se um elemento central no país e em sua Constituição.

Artigo 15. É base essencial e invariável da União entre os Estados, o reconhecimento e a garantia por parte do Governo geral e dos Governos de todos e cada um dos Estados, dos direitos individuais que pertencem aos habitantes e transeuntes nos Estados Unidos da Colômbia, a saber:

$1^{\circ} \mathrm{A}$ inviolabilidade da vida humana; em virtude do qual o Governo geral e o dos Estados se comprometem a não decretar em suas leis a pena de morte.

$2^{\circ}$ Não ser condenados a pena corporal por mais de dez anos.

$3^{\circ} \mathrm{A}$ liberdade individual; que não tem mais limites que a liberdade de outro indivíduo; isto é, a faculdade de fazer ou omitir tudo aquilo de cuja execução ou omissão não resulte dano a outro indivíduo ou à comunidade.

[...]

$6^{\circ}$ A liberdade absoluta de imprensa e de circulação dos impressos, assim nacionais ou estrangeiros.

$7^{\circ}$ A liberdade de expressar seus pensamentos oralmente ou por escrito sem limitação alguma.

$8^{\circ}$ A liberdade de viajar no território dos Estados Unidos, e de sair dele, sem necessidade de passaporte nem permissão de nenhuma autoridade em tempo de paz (COLOMBIA, 1863, tradução nossa').

A liberdade concedida à sociedade colombiana e a institucionalização do fim da escravidão seriam seguidas por projetos de inclusão social? Ou prevaleceria uma segregação

${ }^{8}$ Dedicado a discorrer sobre os padrões políticos da Europa do século XIX, João Fábio Bertonha (2005) evidencia que a Revolução Francesa representou um momento único na história política ocidental, com o rompimento do próprio conceito de político que havia anteriormente e o advento de um novo. Novos padrões se afirmariam, os quais questionavam as ideias que regiam e justificavam o poder no período anterior (como o "direito divino dos reis"). O povo como fonte última do poder, a democracia representativa, a igualdade jurídica entre todos os cidadãos passou a formar a base da idealização política a partir de então, com reflexos imediatos nas estruturas de poder dos Estados europeus e do mundo como um todo.

${ }_{9}^{9}$ Artículo 15. Es base esencial e invariable de la Unión entre los Estados, el reconocimiento y la garantía por parte del Gobierno general y de los Gobiernos de todos y cada uno de los Estados, de los derechos individuales que pertenecen a los habitantes y transeúntes en los Estados Unidos de Colombia, a saber:

1. La inviolabilidad de la vida humana; en virtud de lo cual el Gobierno general y el de los Estados se comprometen a no decretar en sus leyes la pena de muerte.

2. ${ }^{\circ}$ No ser condenados a pena corporal por más de diez años.

3. ${ }^{\circ}$ La libertad individual; que no tiene más límites que la libertad de otro individuo; es decir, la facultad de hacer u omitir todo aquello de cuya ejecución u omisión no resulte daño a otro individuo o a la comunidad.

$[\ldots]$

6. ${ }^{\circ}$ La libertad absoluta de imprenta y de circulación de los impresos, así nacionales como extranjeros.

7. ${ }^{\circ}$ La libertad de expresar sus pensamientos de palabra o por escrito sin limitación alguna.

8. ${ }^{\circ}$ La libertad de viajar en el territorio de los Estados Unidos, y de salir de él, sin necesidad de pasaporte ni permiso de ninguna autoridad en tiempo de paz. (COLOMBIA, 2018) 
étnica e cultural em relação aos ameríndios e aos afrodescendentes? Questionamentos desse gênero também podem ser aplicados aos demais países latino-americanos, nos quais se processou um quadro similar: a marginalização social dos povos indígenas e das comunidades afrodescendentes. Grande parte dos libertos viria a permanecer nas fazendas como mão de obra servil. Seriam arrendatários subordinados aos fazendeiros colombianos, os quais impunham abusos e arbitrariedades. De fato, a situação dos colombianos pobres assemelha-os aos produtores de erva-mate paraguaios, visto que ambos estavam subordinados a um regime quase escravagista comandado pelas demandas do mercado externo (KALMANOVITZ, 1997).

Após a Constituição de 1863 , no país se estabeleceram algumas reformas sociais e políticas que causaram algumas transformações na nação, nas instituições políticas e na cidadania em geral, porque se pretendia mudar as mentalidades dos habitantes no território do país, superar o passado católico e hispânico e constituir uma nação orientada para o trabalho, a ética capital e a produção. Entre outros objetivos, se fomentou o desenvolvimento econômico e se alentou o progresso cultural, ao decretar a educação laica e gratuita, aumentar a alfabetização e incorporar o país às vanguardas e correntes de pensamento a nível mundial (MUÑOZ, 2016, p. 14-15, tradução nossa ${ }^{10}$ ).

Entre 1860 e 1880, os regimes do Ocidente adotaram o liberalismo como princípio norteador das políticas estatais; os governos passaram a se subordinar aos interesses econômicos do país, buscando continuamente respeitar o ideal liberal do Laissez Faire. Esse princípio do Estado mínimo também seria instaurado na Colômbia no final do século XIX, quando a economia cafeeira do país passaria a ser conduzida pelas leis do mercado internacional. A partir de então se restringiria a ingerência do Estado colombiano na vida privada e se defenderia a liberdade dos indivíduos em conduzir a si mesmos. No Brasil do século XIX, ganharia destaque o pensamento de Tavares Bastos (1839-1875), cuja obra $A$ Província (1870) - produzida durante o regime monárquico de Pedro II - viria a se destacar por defender a descentralização do país, reivindicando a implantação de um sistema federalista. Assim, Tavares Bastos representou o advento dos ideais liberais no Brasil. De fato, suas análises inserem-se nesse contexto liberal que caracterizou a América Latina no fim do século XIX.

Evidentemente, esse período de implantação do liberalismo político em grande parte do Ocidente coincidiu com o momento de advento do capitalismo liberal na Colômbia, quando o

${ }^{10}$ Tras la Constitución de 1863, en el país se establecieron algunas reformas sociales y políticas que causaron algunas transformaciones políticas y en la ciudadanía en general, porque se pretendió cambiar las mentalidades de los habitantes en el territorio del país, superar el passado católico e hispánico y constituir una nación orientada al trabajo, la ética capital y la producción. Entre otros objetivos, se fomentó el desarrollo económico y se alento el progreso cultural, al decretar la eucación laica y gratuita, aumentar la alfabetización e incorporar el país a las varguardias y corrientes depensamiento a nivel mundial (MUÑOZ, 2016, p. 14-15). 
país passaria a se inserir de fato no mercado mundial. A economia colombiana se destacaria pelas exportações de produtos primários - especialmente algodão, anil e tabaco -, crescendo cerca de $29 \%$ entre 1850 e 1885 (KALMANOVITZ, 1997). Grande quantia da produção agrícola do país era consumida pelas indústrias europeias ou estadunidenses, retornando à Colômbia de forma processada. Formada consubstancialmente por imigrantes de origem alemã e judaica, uma forte burguesia seria conformada nas décadas finais do século XIX, contribuindo para modificar os costumes e padrões de consumo na nação colombiana.

A oposição a esse modelo liberal seria composta por uma casta agrária, católica e de descendência hispânica, conhecida como La Regeneración. Viria a se instaurar uma oposição entre liberais e protecionistas, quadro que se reproduziria em todo o contexto americano. Todavia, os conflitos que se desenvolveram entre 1850 e 1880 não devem ser visualizados como uma dicotomia revolucionária entre liberais e conservadores, como o faz Jaime Jaramillo Uribe $(\mathrm{s} / \mathrm{d})^{11}$. As reformas liberais desse contexto seriam revertidas com uma guerra civil em 1885 , cuja reversão seria concretizada com a Constituição de 1886. Assim, as medidas liberais inauguradas com a Constitución de Rionegro seriam revogadas, emergindo um regime centralista, autoritário e presidencialista. Um novo período se instalaria na História da Colômbia:

\begin{abstract}
Sem dúvida, muitas foram as contradições que não superaram os liberais radicais, entre elas, os privilégios do poder dadas as relações entre as classes e a burocracia; a fraude no sistema eleitoral; as disputas nas soberanias regionais; o pluralismo de uma cultura ancorada na mestiçagem; as demandas da economia mundial; a construção da comunidade política e a autonomia das liberdades individuais e civis; o controle do contrabando, as armas e o problema do castigo e da pena de morte, entre outras coisas. Estas contradições foram aproveitadas pelos conservadores na oposição, quem alentaram implicitamente ou de frente através da imprensa e da opinião pública, o descrédito do projeto radical e alentaram a crise que derivou em uma guerra civil no ano de 1885, que os derrotava e instaurava um regime conservador na mão de Rafael Núñez e Miguel Antonio Caro. Núñez e Caro conceberam sua reforma política como Regeneración e estes dois conservadores empreenderam o caminho de uma "distopia" que considerava entre muitos outros projetos, a volta à herança espanhola, a centralização, a sacralização do país, a censura à imprensa, a diminuição às liberdades, a contenção da oposição política, como também impunham um regime
\end{abstract}

11 “Al llegar el año de 1850, en el país se respiraba una atmósfera de cambios revolucionarios. La emergente opinión pública se encontraba ya organizada en partidos. Un fuerte grupo de comerciantes germen de una clase burguesa y un artesanado vigoroso hacían su aparición en el escenario político y social, exigiendo reformas que los gobiernos anteriores habían aplazado, formaban el naciente partido liberal. En contrapunto con estas fuerzas, la vieja clase terrateniente, el clero y las familias de abolengo, de acendrada formación católica, se agrupaban en torno al que luego será el partido conservador" (URIBE, s/a, p. 21). 


\section{La regeneración}

presidencialista que limitava a democracia defendida pelos liberais através da Constituição de 1863 (MUÑOZ, 2016, p. 38, tradução nossa ${ }^{12}$ ).

No decorrer das décadas finais do século XIX, especialmente a partir de 1880, o Ocidente cristão virá a passar por um processo de secularização política. Muitos dos governos que até então estavam vinculados à Igreja começaram a romper suas relações com aquela instituição, tendendo a se tornarem laicos ${ }^{13}$. Os cemitérios e os casamentos submetem-se à jurisdição do Estado, que necessita garantir a tolerância cultural para sua população cada vez mais diversificada. Assim, fenômenos de hibridização cultural e religiosa passam a ser legítimos nessa nova sociedade que se proclama tolerante e laica ${ }^{14}$. Essa é a tendência que passa a ser cada vez mais rotineira nos países ocidentais.

Todavia, um quadro muito distinto ainda irá prevalecer na Colômbia pós-1885, quando passam a reinar os ideais de um cristianismo medieval espanhol. Afinal, “[...] os conservadores apelaram ao ethos católico liderado pelos adeptos da Regeneración, os quais apelaram à obediência e à submissão dos cidadãos, apoiados além disso na herança do mundo cristão medieval espanhol" (MUÑOZ, 2016, p. 39, tradução nossa ${ }^{15}$ ). A Regeneración consistiu em um regime e em um projeto de caráter político-cultural que conduziu o Estado colombiano entre 1885 e 1902. O período inicia-se com a "restauração moral" proposta pelos conservadores, chegando até a "Guerra dos Mil dias" (1899-1902), a qual fora a responsável por derrubar o regime da Regeneración. Como bem suscita o sociólogo Darío Mesa (1982, p. 90 apud MUÑOZ, 2016, p. 41-42), os líderes políticos desse grupo conservador somente sabiam manter o poder mediante as relações de clientela. Quando olhamos em retrospecto, a Colômbia pós-

\footnotetext{
${ }^{12}$ Sin embargo, muchas fueron las contradicciones que no superaron los liberales radicales, entre ellas, los privilegios del poder dada las relaciones entre las clases y la burocracia; el fraude en el sistema electoral; las disputas de las soberanías regionales; el pluralismo de una cultura anclada en el mestizaje; las demandas de la economía mundial; la construcción de comunidade política y la autonomía de las libertades individuales y civiles; el control del contrabando, las armas y el problema del castigo y la pena de muerte, entre otras. Estas constradicciones fueron aprovechadas por los conservadores en la oposición, quienes alentaron soterrada o de frente a través de a prensa y la opinión pública, el descrédito del proyecto radical y alentaron la crisis que derivó en una guerra civil en el año de 1885, que los derrocaba e instauraba el régimen conservador de la mano de Rafael Núñez y Miguel Antonio Caro. Núñez y Caro concibieron su reforma política como Regeneración y estos dos conservadores emprendieron el caminho de una "disutopía" que consideraba entre muchos otros proyectos, la vuelta a la herencia Española, la centralización, la sacralización del país, la censura a la prensa, la disminuición de las libertades, la contención de la oposición política, como também imponía un régimen presidencialista que limitaba la democracia refrendada por los liberales a través de la Constitución de 1863 (MUÑOZ, 2016, p. 38).

13 Para mais informações, consultar Giacomo Marramao (1997).

${ }^{14}$ Empregamos o termo "hibridismo cultural" a partir da conceituação de Peter Burke (2003).

15 [...] los conservadores apelaron al ethos católico liderado por los adeptos de la Regeneración, quienes apelaron a la obediência y a la sumisión de los ciudadanos, apoyados además en la herencia del mundo cristiano medieval español (MUÑOZ, 2016, p. 39).
} 
1885 correspondia a um país eminentemente rural, um terreno de caudilhos, de guerras civis e de caciques locais.

O período da Regeneración foi gerado a partir de uma guerra civil em 1885, a qual “impulsionou o setor da fazenda senhorial liderado por Miguel Antonio Caro e Rafael Núñez, e impôs um regime que se denominou 'O poder dos gramáticos"” (MUÑOZ, 2016, p. 44-45; tradução nossa ${ }^{16}$ ). Como complementa Malcolm Deas (2006), os eruditos colombianos - uma espécie de intelligentsia universitária - seriam responsáveis por ingressar no poder político durante esse período da história colombiana. E, de fato, o controle da educação mostrava-se fundamental para a manutenção da hegemonia política. Conforme apresenta Aline Helg (2001), as escolas colombianas tinham seus programas definidos em consonância com o regime político então vigente. $\mathrm{O}$ clientelismo político implantado com o conservadorismo da Regeneración veio a ter influências na educação escolar do jovem colombiano, conduzindo-o a ser conivente com o caudilhismo e com os fenômenos nepotistas. Os governantes que acabaram por compor a Regeneración viam os outros - isto é, os não católicos e os não conservadores - como absolutos inimigos, os quais deveriam ser exterminados do território nacional.

A Regeneración utilizou a retórica católica e sob sua roupagem estimulou uma política de extermínio que incluía sua manutenção no poder mediante a fraude eleitoral e a corrupção e inclusive com a consigna de uma pátria, uma fé, uma nação, um cidadão, primordialmente católico e conservador. $\mathrm{O}$ peculiar da dominação e do controle político da Regeneración foi isolar por todos os meios do espaço político aos liberais e combater as ideias do Laissez Faire, o federalismo, a descentralização administrativa, as liberdades individuais e a secularização do país, ou todas aquelas ideologias que eram próximas da modernidade e da revolução política (MUÑOZ, 2016, p. 46-47, tradução nossa ${ }^{17}$ ).

Quando se analisa a Constituição de 1886, percebe-se imediatamente seu cunho religioso e unitário. Afinal, seu primeiro artigo ratifica o centralismo da Colômbia: "A Nação Colombiana se reconstitui em forma de República unitária” (COLOMBIA, 1886, tradução nossa ${ }^{18}$ ). Conforme define o Artigo 194, os Governadores passariam a ser nomeados pelo governo central, sendo os mediadores do poder presidencial e o poder nos Departamentos.

\footnotetext{
${ }^{16}$ [...] impulso el sector de la hacienda señoral liderada por Miguel Antonio Caro y Rafael Núñez, e impuso un régimen que se denomino "El poder de los gramáticos" [...] (MUÑOZ, 2016, p. 44-45).

${ }^{17}$ La Regeneración utilizo la retórica católica y bajo su ropaje alento una política de exterminio que incluía su manetimiento en el poder mediante el fraude electoral y la corrupción e incluso con la consigna de una patria, una fe, una nación, un ciudadano, primordialmente católico y conservador. Lo peculiar de la dominación y el control político de la Regeneración fue aislar por todos los medios del espacio político a los liberales y combatir las ideas del Laissez Faire, el federalismo, la descentralización administrativa, las libertades individuales y la secularización del país, o todas aquellas ideologías que eran cercanas a la modernidad y la revolución política (MUÑOZ, 2016, p. 46-47).

${ }^{18}$ La Nación Colombiana se reconstituye em forma de República unitaria (COLOMBIA, 1886).
} 
Artigo 195. São atribuições do Governador:

$1^{\text {a }}$ Cumprir e fazer que se cumpram no Departamento as ordens do Governo; $2^{\mathrm{a}}$ Dirigir a ação administrativa no Departamento, nomeando e separando seus agentes, reformando ou revogando os atos destes e ditando as providências necessárias em todos os ramos da Administração.

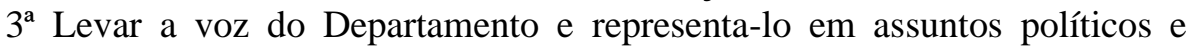
administrativos.

$4^{\mathrm{a}}$ Auxiliar a justiça os termos que determina a lei.

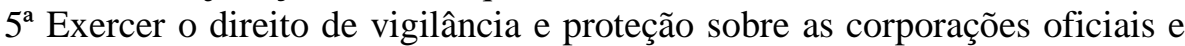
estabelecimentos públicos (COLOMBIA, 1886, tradução nossa ${ }^{19}$ ).

A Guerra dos Mil Dias, travada entre 1899 e 1902, expressou o antagonismo entre as forças ideológicas colombianas. Representou a crescente insatisfação dos liberais e dos conservadores moderados diante das fraudes do sistema eleitoral, do endurecimento da censura à imprensa e dos abusos sobre os impostos da exportação do café. O próprio fundador do periódico EI Spectador, Fidel Cano Gutiérrez, se oporia firmemente às restrições impostas à imprensa colombiana. Para Muñoz (2016, p. 48), a lei de 6 de maio de 1888, conhecida como Ley de los Caballos - pela qual se outorgavam amplos poderes ao presidente, que poderia considerar quais os crimes que eram contra a sociedade e quem deveria ser penalizado e fuzilado -, seria a mais autoritária lei do período da Regeneración. O autoritarismo político instaurado seria um dos motivos que instigaria a Guerra dos Mil Dias.

[...] foi a retórica ultra-católica de Miguel Antonio Caro, sua intransigência e intolerância que gerou as desavenças e desacordos e inclusive foi sua atitude política a que atiçou a conflagração bélica. Setores de oposição tanto liberais radicais como conservadores moderados, ao serem excluídos e marginalizados do jogo e controle do poder político se viram na necessidade de se alçar através das palavras e logo com as armas devido à sistemática perseguição e liquidação dentro da ordem política respaldada pelos líderes e dirigentes da Regeneración (MUÑOZ, 2016, p. 46, tradução nossa ${ }^{20}$ ).

${ }^{19}$ Artículo 195. Son atribuciones del Gobernador:

$1^{\text {a }}$ Cumplir y hacer que se cumplan en el Departamento las órdenes del Gobierno.

$2^{\mathrm{a}}$ Dirigir la acción administrativa en el Departamento, nombrando y separando sus agentes, reformando o revocando los actos de éstos y dictando las providencias necesarias en todos los ramos de la Administración.

$3^{a}$ Llevar a voz del Departamentoy representarlo en assuntos políticos y adminsitrativos.

$4^{\mathrm{a}}$ Auxiliar la justicia en los términos que determine la ley;

$5^{\text {a }}$ Ejercer lo derecho de vigilancia y protección sobre las corporaciones oficiales y establecimientos públicos. (COLOMBIA, 1886)

${ }^{20}$ [...] fue la retórica ultra-católica de Miguel Antonio Caro, su intransigencia e intolerancia la que generó las desavenencias y desacuerdos e incluso fue su actitud política la que atizó la conflagración bélica. Sectores de oposición tanto liberales radicales como conservadores moderados, al ser excluidos y marginados del juego y control del poder político se vieron en la necesidad de alzarse a través de las palavras y luego con las armas debido a la sistemática persecución y liquidación dentro del orden político respaldado por los líderes y dirigentes de la Regeneración. (MUÑOZ, 2016, p. 46) 
$\mathrm{O}$ ascender do século XX assinalou o fim da guerra civil, fechando um ciclo que teve como consequência a perda do Panamá em 1903 e a emergência de Rafael Reyes (1904-1909) ao poder, o qual buscou ser um reconciliador nacional.

\section{Do republicanismo ao protofascismo}

[...] a Guerra dos Mil Dias não foi uma guerra palaciana, se envolveram amplos setores baixos da população e inclusive se pode afirmar que através dela, houve inclusões e ascensão das classes mais baixas da sociedade colombiana. Como "guerra reparação", a conflagração bélica reestruturou o jogo de poder do sistema político colombiano. A guerra propiciou não somente a perda de uma parte da soberania nacional - Panamá - mas também, visibilizou igualmente a geografia do país e fomentou a ascensão das elites regionais (MUÑOZ, 2016, p.51, tradução nossa ${ }^{21}$ ).

Mediante a ascensão de Rafael Reyes ao poder em 1904, cujo programa se baseava no lema "Mais administração, menos política", passou-se a objetivar promover a inclusão política das minorias liberais, a modernização estatal e a integração nacional. Reyes instigou a descentralização política, traçando uma ruptura com o período anterior. O projeto denominado Republicanismo emergiria no cenário político colombiano, formulado por Carlos E. Restrepo em Orientación Republicana. Esse novo projeto previa a intervenção do Estado no campo social, sobretudo com o intuito de controlar as massas e os conflitos sociais gerados pela proletarização e massificação da sociedade (MUÑOZ, 2016, p. 53). Enquanto ulterior presidente, Restrepo pretendeu que o governo de Reyes fosse capaz de solucionar os problemas acumulados na Colômbia, especialmente no que diz respeito ao seu plano social.

Intervir na sociedade e auxiliar o cidadão passou a consistir em uma importante forma de integrar os colombianos no processo de organização e modernização do país - pauta fundamental após anos de restrições socioeconômicas. Assim, o liberalismo e o capitalismo foram articulados pelo projeto do Republicanismo. Apesar do governo liberal de esquerda de Alfonso López Pumarejo, as tendências de extrema direita emergiriam na política colombiana com os regimes protofascistas de Eduardo Santos (1938-1942) e de Laureano Gómez (19491953). Para Muñoz (2016), esses governos direitistas impunham a segunda Regeneración ao

21 “[...] la Guerra de los Mil Días no fue una guerra palaciega, se vieron involucrados amplios sectores bajos de la población e incluso se puede afirmar que a través de ella, hubo inclusiones y ascensos de las clases más bajas de la sociedad colombiana. Como "guerra reparación", la conflagación bélica reestructuró el juego de poder del sistema político colombiano. La guerra propició no solamente la perdida de un parte de la soberanía nacional Panamá - sino también, visibilizo igualmente la geografia del país y fomento el ascenso de las elites regionales" (MUÑOZ, 2016, p. 51). 
país. Ao fim, "Em 13 de junho de 1953, um golpe de Estado propiciado pelo General Gustavo Rojas Pinilla demonstrava as incoerências como as incapacidades com que as elites políticas civilistas da Colômbia haviam liderado e conduzido o país em 50 anos” (MUÑOZ, 2016, p. 57, tradução nossa $\left.{ }^{22}\right)$.

\section{Considerações finais}

Nosso trabalho contou como base o texto de R. R. Muñoz (2016), contido na importante coleção acerca da História da América Latina dirigida pelos professores Marcela Cristina Quinteros e Luiz Felipe Viel Moreira. Muitas dificuldades apareceram ao longo do processo de escrita, sobretudo no que tange à escassez de material disponível no Brasil. Em nossa tentativa, buscamos produzir um texto didático, cujo fim repousasse em evidenciar as lacunas da História da Colômbia e a multiplicidade de temas disponíveis para o estudo.

\section{REFERÊNCIAS}

BANDEIRA, Luiz Alberto Moniz. De Martí a Fidel: a Revolução Cubana e a América Latina. Rio de Janeiro: Civilização Brasileira, 2009.

BASTOS, Tavares. A Província. Rio de Janeiro: Garnier, 1870.

BAUTISTA, Óscar Fresneda. Evolución de la estrutura de clases sociales em Colombia, 1938-2010. Han crecido las clases medias? Sociedad y economia, n. 33, p. 205-236, 2017.

BERTONHA, João Fábio. Os italianos. São Paulo: Editora Contexto, 2005.

BETHELL, Leslie. História da América Latina. Volume 5. São Paulo: Editora da Universidade de São Paulo, 2004.

BOURDÉ, Guy, MARTIN, Hervé. As escolas históricas. Belo Horizonte: Autêntica Editora, 2018 .

BURKE, Peter. Hibridismo Cultural. São Leopoldo: Editora Unisinos, 2003.

COLOMBIA. Constitución Política de los Estados Unidos de Colombia, 1863. Disponível: https://archivos.juridicas.unam.mx/www/bjv/libros/5/2212/12.pdf. Acesso: 25 dez. 2018.

COLOMBIA. Constitución Política de la República de Colombia, 1886. Disponível: http://americo.usal.es/oir/legislatina/normasyreglamentos/constituciones/colombia1886.pdf. Acesso: 29 dez. 2018.

${ }^{22}$ El 13 de junio de 1953, un golpe de Estado propiciado por el General Rojas Pinilla demostraba las incoherencias como las incapacidades con que las elites políticas civilistas de Colombia habían liderado y conducido el país en 50 años (MUNOZ, 2016, p. 57). 
DEAS, Malcolm. Del poder y la gramática, Y otros ensayos sobre historia, política y literatura colombianas. Bogotá: Taurus, 2006.

FARRET, Rafael Leporace; PINTO, Simone Rodrigues. América Latina: da construção do nome à consolidação da ideia. Topoi, v. 12, n. 23, p. 30-42, 2011.

GÓMEZ, Gonzalo Sánchez. Guerra y Política en la Sociedad Colombiana. Estudios, Analisis Politico, n. 11, p. 07-27, 1990.

HELG, Aline. La educación en Colombia, 1918-1957: una historia social, económica y política. Bogotá: Panamericana, 2001.

HERVIEU-LÉGER, Danièle. O peregrino e o convertido: a religião em movimento. Petrópolis: Vozes, 2008.

KALMANOVITZ, Salomón. Economía y Nación: una breve historia de Colombia. Bogotá: Tercer Mundo, 1997.

MANETTO, Francesco; TORRADO, Santiago. Construir a paz é mais difícil que consegui-la. Requer modificar preconceitos. EL PAÍS, 2018. Disponível: https://brasil.elpais.com/brasil/2018/12/07/internacional/1544147352_435475.html. Acesso: 25 dez. 2018.

MARRAMAO, Giacomo. Céu e Terra: Genealogia da secularização. São Paulo: Editora Unesp, 1997.

MCGREEVEY, William Paul. Historia Económica de Colombia, 1845-1930. Bogotá: Universidad de los Andes, 2015.

MUÑOZ, Rafael Rubiano. Colombia de um Siglo a Outro: Modernidad Elusiva, Revolución, Contrarrevolucion y Procesos Políticos Inconclusos (1853-1953). In: QUINTEROS, Marcela Cristina; MOREIRA, Luiz Felipe Viel (Orgs.). As revoluções na América Latina contemporânea. Maringá: UEM-PGH-História, 2016.

PERROT, Michelle. Os excluídos da História. Rio de Janeiro: Paz e Terra, 2017.

PADRO, Maria Ligia; PELLEGRINO, Gabriela. História da América Latina. São Paulo: Contexto, 2018.

PRADO, Maria Ligia Coelho. Repensando a História Comparada da América Latina. Revista de História, n. 153, v. 2, p. 11-33, 2005.

QUINTEROS, Marcela Cristina, MOREIRA, Luiz Felipe Viel. Violência Política na História do Paraguai (1904-1954). In: QUINTEROS, Marcela Cristina; MOREIRA, Luiz Felipe Viel (Orgs.). As revoluções na América Latina contemporânea. Maringá: UEM-PGH-História, 2016.

RESENDE, Maria Efigênia Lage de. O processo político na Primeira República e o liberalismo oligárquico. In: FERREIRA, Jorge; DELGADO, Lucilia de Almeida Neves. 
(Orgs.). O Brasil Republicano. Da proclamação da República à Revolução de 1930. São Paulo: Civilização Brasileira, 2003.

SOUZA, Ailton de. América Latina, conceito e identidade: algumas reflexões da história.

PRACS: Revista de Humanidades do Curso de Ciências Sociais da UNIPAF, Macapá, n. 04, 2011, p. 29-39.

URIBE, Jaime Jaramillo. Etapas y Sentido de la Historia de Colombia. Disponível: http://www.geocities.ws/gersonledezma/TextosAmericaLatina/EtapasySentidodelaHistoria.pd f. Acesso: 28 dez. 2018.

\section{Como referenciar este artigo}

MULZA, Giovana Eloá Mantovani. Por uma história crítica da Colômbia (1853-1953). Rev. Sem Aspas, Araraquara, v. 8, n. 2, p. 193-208, jul./dez. 2019. e-ISSN: 2358-4238. DOI: https://doi.org/10.29373/sas.v8i2.13037

Submetido em: 12/10/20219

Revisões requeridas: 30/11/2019

Aprovado em: 08/12/2019

Publicado em: 30/12/2019 